\title{
EXPERIMENTAL RESEARCHES REGARDING REALIZATION OF WASTEWATER TREATMENT ELEMENTS BY MEANS OF MODERN TECHNOLOGIES
}

\author{
Daniel Besnea ${ }^{1}$, Gheorghe I.Gheorghe ${ }^{2}$, Octavian Dontu ${ }^{1}$,Edgar Moraru, ${ }^{1}$, Victor Constantin ${ }^{1}$, Ioana Corina Moga ${ }^{3}$ \\ ${ }^{1}$ Politehnica University of Bucharest, Department of Mechatronics and Precision Mechanics \\ 2 The National Institute of Research and Development in Mechatronics and \\ Measurement Technique \\ ${ }^{3}$ D.F.R. Systems SRL Bucharest \\ E-mail:ㅁbes@yahoo.com,geocefin@yahoo.com,octavdontu@gmail.com , \\ eddy milan91@yahoo.com, victor.f.constantin@gmail.com; corinamoga@yahoo.com
}

\begin{abstract}
The paper presents a modern constructive solution using the additive technologies and the computer numerical control processing technologies for the realization of some components used for wastewater treatment. The aeration diffusers cassettes were obtained from different materials and with different 3D printing equipment. Plates with orifices were made on CNC machines, the arrangement of orifices and the diameter being different. The obtained orifices were investigated microscopically, comparing the results of the measurements with the proposed theoretical ones. After the joining and sealing of the realized subassemblies, it can be mounted in the water aeration testing installation, being ready to perform its functions in the most optimal way.
\end{abstract}

Keywords: Additive technologies, ABS, PLA, Fine bubble generator, Diffusers, Wastewater.

\section{Introduction}

Although the aeration processes can be carried out naturally without any intervention from the outside, it is necessary to know in more detail the equipment necessary for the construction of high-performance installations, but also for optimal and efficient operation. Water oxygenation is a fundamental process of thermodynamics, a process of mass transfer between air and water. The process is based on the transfer of oxygen from the air or the direct transfer of pure oxygen into a mass of water. The presence of dissolved oxygen is extremely important in the process of purification and self-purification of natural or residual waters, because it is the main catalyst for life or the level of pollution in that water. When the amount of dissolved oxygen in the water is slightly lower than the maximum amount it can hold (saturation concentration), we can say that we have partial mild pollution or partial asphyxiation of this water. Aeration is necessary to improve water quality to avoid the occurrence of oxygen deficiency in systems where there is a biochemical oxygen demand dissolved over self-aerating capacity, for the elimination of any toxic gases in the water and the waste water treatment process and before the water is reintroduced into the natural hydrological circuit. The aeration devices used to dissolve air in water may be mechanical, pneumatic, mixed, pure oxygen or ozone and jet devices. The most used are pneumatic ones because of their superior efficiency.

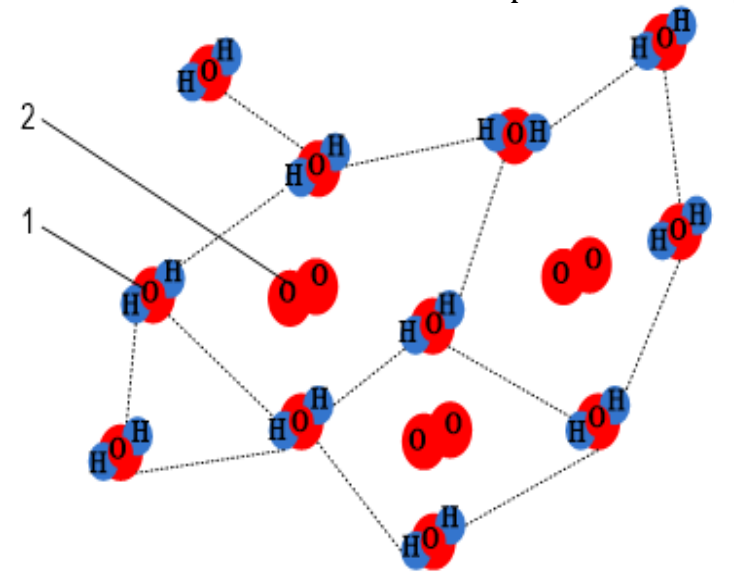

Figure 1: The molecular structure of water containing dissolved oxygen:

1 - water molecule; 2 - dissolved oxygen molecule [1]

In pneumatic aeration plants, the air must be introduced as bubbles as small as possible to increase the air-liquid contact surface in a given volume of air. For this purpose, plates with orifices, called diffusers or fine bubble generators (F.B.G.)[1]. In this paper, the fine bubbles generators [2] are made of aluminium alloyed with magnesium and 
were obtained on CNC machines. The cassettes or carcasses of diffusers or fine bubble generators were made by means of additive technologies, namely by the thermoplastic extrusion technique, which uses as a raw material an ecological biodegradable polymer.

\section{Materials and Methods}

Additive technologies allow the production of any geometry parts in layers based on a 3D designed model. If the conventional machining technology is done by removing the material, Rapid Prototyping technology is made by adding material as much as needed and where needed. Apart from the advantages of material savings, these technologies also have the following benefits: the possibility of obtaining complex geometries that cannot be achieved by other technologies; improved properties of finished parts; mobility and affordability of manufacturing at a relatively low cost. Among the main applications, it can be highlighted the automotive, aerospace, medical and military fields. Methods based on the principle of adding material can be categorized by the type of process used in seven major categories: vat photopolymerisation [3], material extrusion [4], powder bed fusion [5], material jetting, binder jetting, lamination and direct energy deposition. In this article, the material extrusion technique or fused deposition modelling technology (FDM) was used to materialize the aerator cassette. FDM technology (Figure 2) involves creating three-dimensional objects by applying successive layers of material following the contour of a designed digital model. The part is made by extrusion and applying of molten thermoplastic material with the formation of three-dimensional layers that solidify immediately after they are deposited.

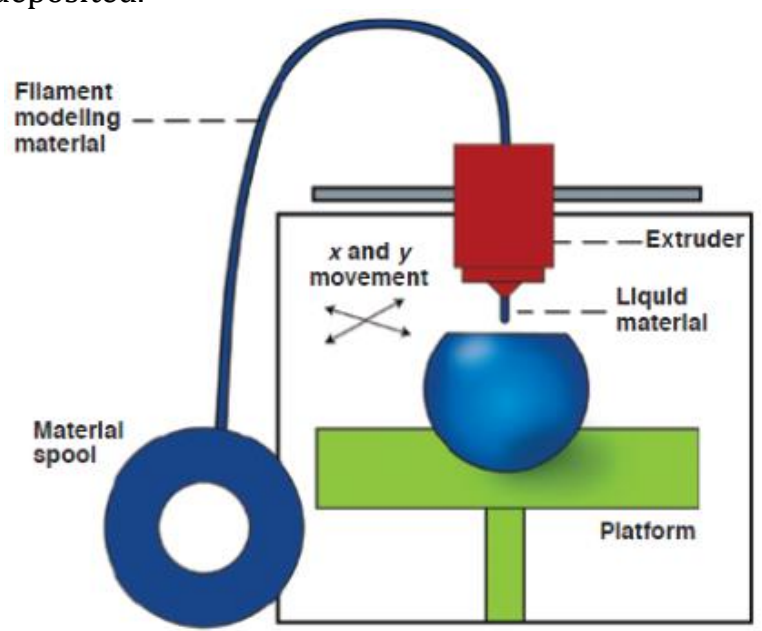

Figure 2: Fused deposition modelling process [6]

The extruder moves in horizontal and vertical planes under the control of algorithms similar to those used in numerically controlled machines. The nozzle moves along the trajectory defined by the CAD system, the model being built layer with layer, from bottom to top. As raw material, the most common materials are ABS (acrylonitrile-butadiene-styrene) and PLA (polylactic acid). PLA is a biopolymer, ie a biodegradable plastic material and is made from renewable materials and is considered to be more environmentally friendly than ABS. Instead ABS has better mechanical properties and is used more frequently in engineering applications. Due to the relatively low melting point, PLA is not recommended for objects that are exposed to heat. When heated to over $60^{\circ} \mathrm{C}$, PLA products begin to lose shape. ABS is more suitable for high temperature parts and can be used for models subject to mechanical shocks [7]. In this study, both ABS and PLA were used as a raw material to obtain cassette for aeration diffusers.

\section{Experimental}

Realization of cassettes for wastewater aeration elements begins with the obtaining of the threedimensional digital model. For this scope, the CATIA V5 was used. The designed cassette is illustrated in the Figure 3.

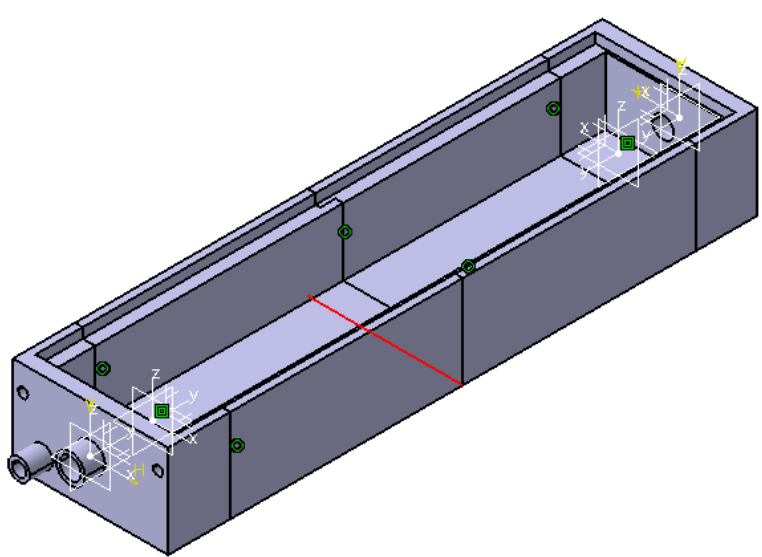

Figure 3: CAD model of diffuser cassete

The model consists of four subassemblies due to its large gabarits (360x80 $\mathrm{mm}$ ) which exceeds the maximum print sizes of the thermoplastic extrusion equipment used. The next step is to generate the $G$ code in a specialized slicing program of equipment. In this case, the Replicator $G$ software for the Wanhao Duplicator $4 \mathrm{~S}$ printer and the Cura for the Delta printer were used. The interfaces of these softwares with generating the G code of a cassette subassembly are shown in Fig.4 and Fig.5. This software slides the model into 0.1-0.2 mm thick surfaces and turns it into a language recognized by the 3D printer. In principle, the software determines the printhead trajectory when the material is applied. After the model has been prepared, the object is sent for fabricating. 

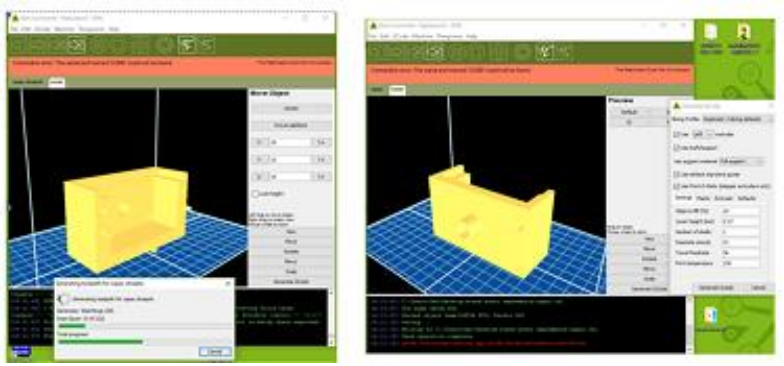

Figure 4: Replicator G software interface

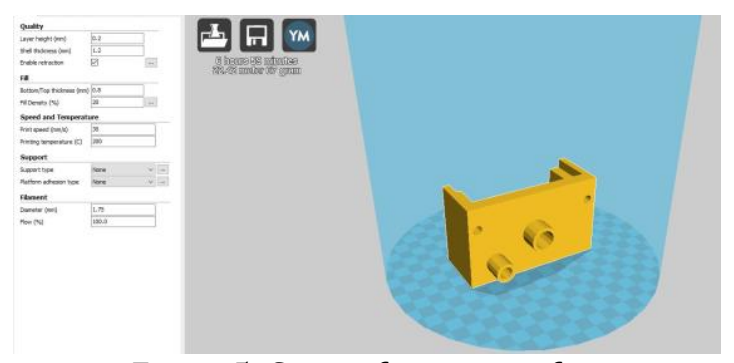

Figure 5: Cura software interface

Figures 6-8 illustrate images during the manufacturing process.

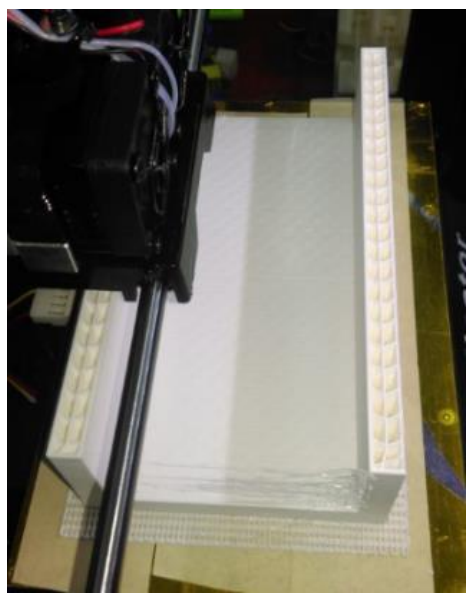

Figure 6: PLA part during printing on Wanhao Duplicator $4 S$

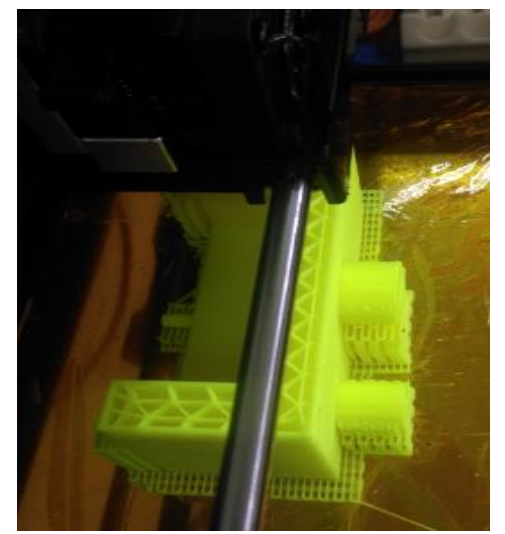

Figure 7:ABS part during printing on Wanhao Duplicator $4 S$
After finishing the manufacture of the cassette subassemblies, the sacrificial layers are carefully removed to avoid damaging of the active surfaces of the cassette. Then the subassemblies are glued with adhesive resulting in the final cassette. In total, three ABS and PLA cassettes were made on two different printers types, which will subsequently be mounted and sealed with CNC machined plates with orifices.

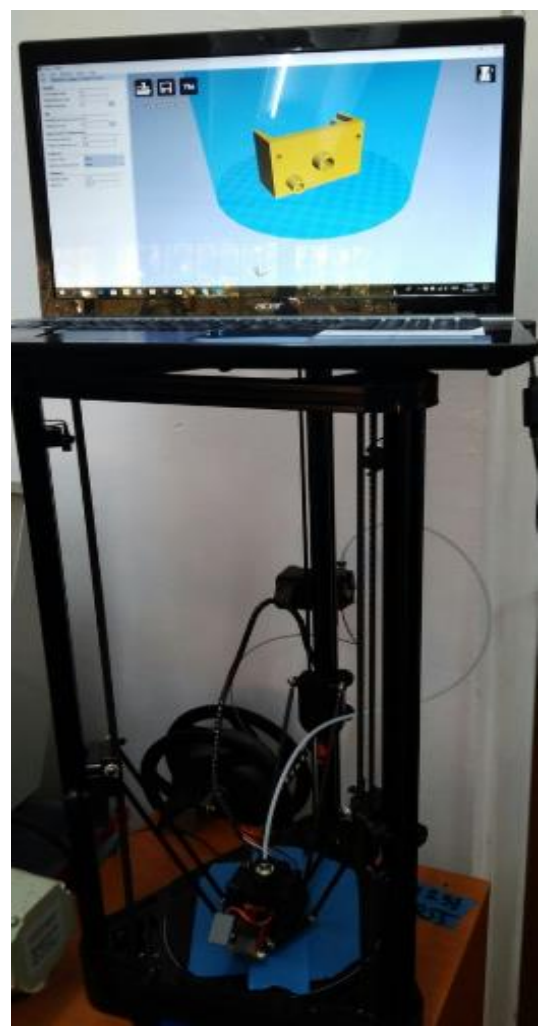

Figure 8: PLA part during printing on Delta

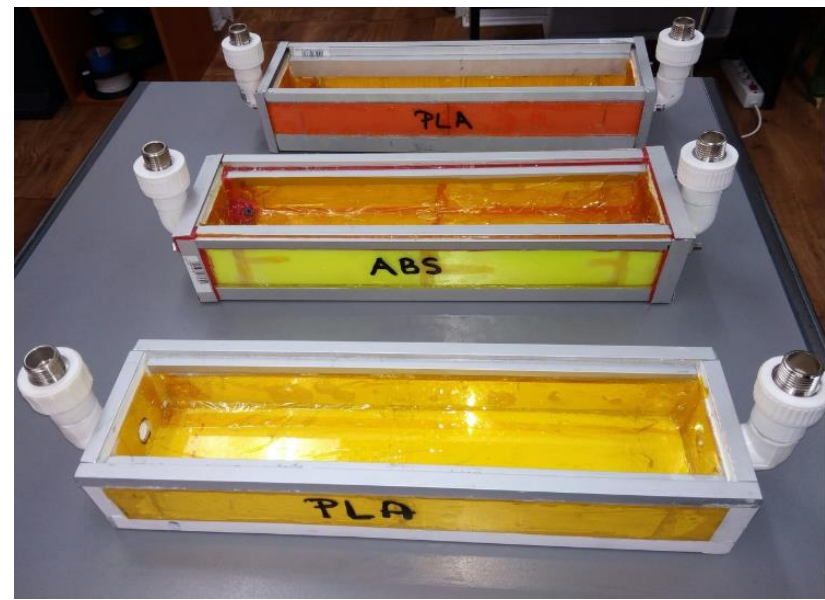

Figure 9: Diffuser cassettes obtained from PLA and $A B S$

After the printed parts of the cassettes have been assembled through adhesion, the air supply pressure connections have been installed and some aluminum $\mathrm{L}$ profiles have been glued to the edges of the 
cassette for stiffening and to have a seating and sealing surface with plate.

Plates with orifices were obtained by means of the CNC installation, the material being aluminum alloy AlMg4.5Mn0.7, in total 6 plates with diameters of $0.1,0.3,0.5,0.7,0.9$ and $1.1 \mathrm{~mm}$ were made.

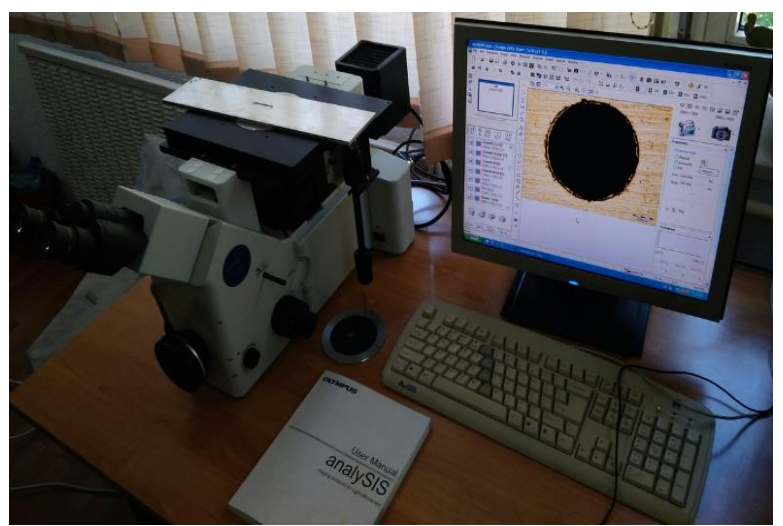

Figure 10: Microscopic analysis of the obtained orifices

In order to investigate the obtained orifices, the microscopic method was used. For this purpose, the Olympus GX-51 microscope is used, which is an inverted metallurgical microscope with the ability to perform research in several regimes and modes [8, 9].

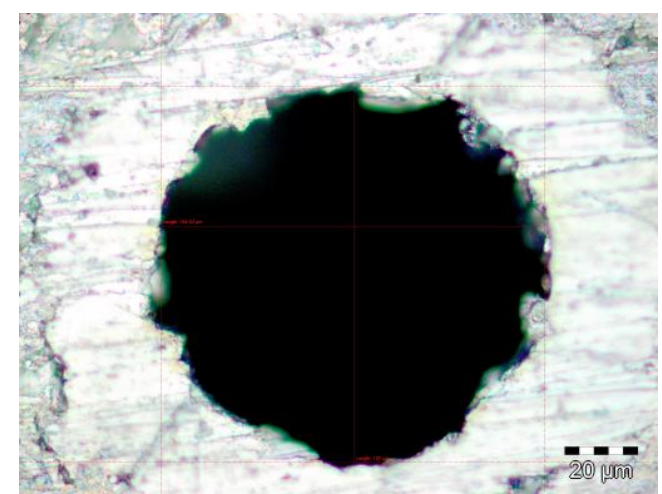

Figure 11: Microscopic image of the $\emptyset 0.1 \mathrm{~mm}$ orifice, 1000x magnification

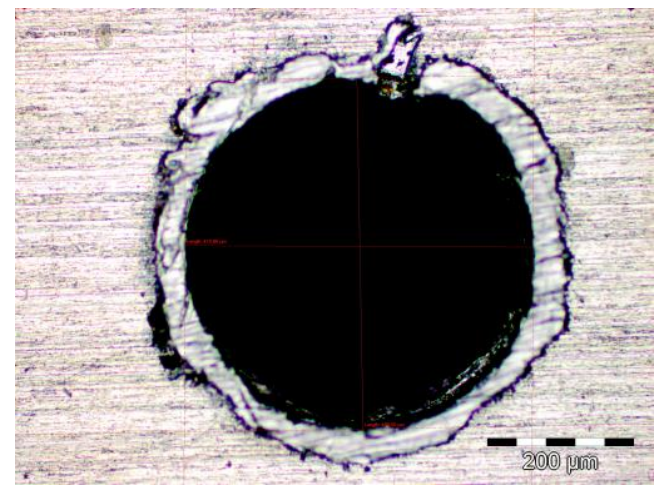

Figure 12: Microscopic image of the $\varnothing 0.5 \mathrm{~mm}$ orifice, 200x magnification

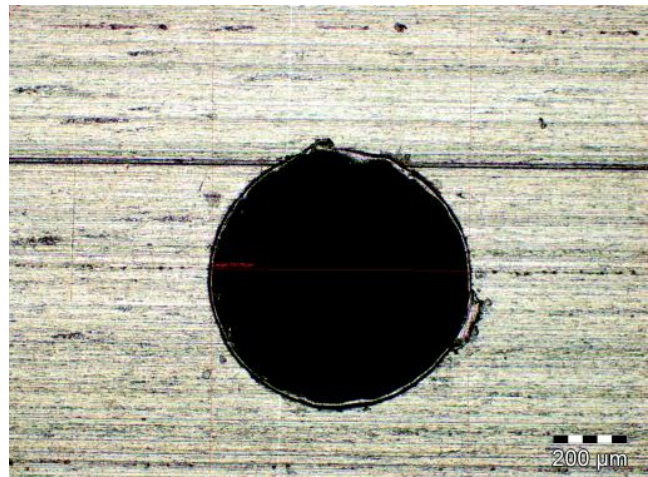

Figure 13:Microscopic image of the $\varnothing 0.7 \mathrm{~mm}$ orifice, 100x magnification

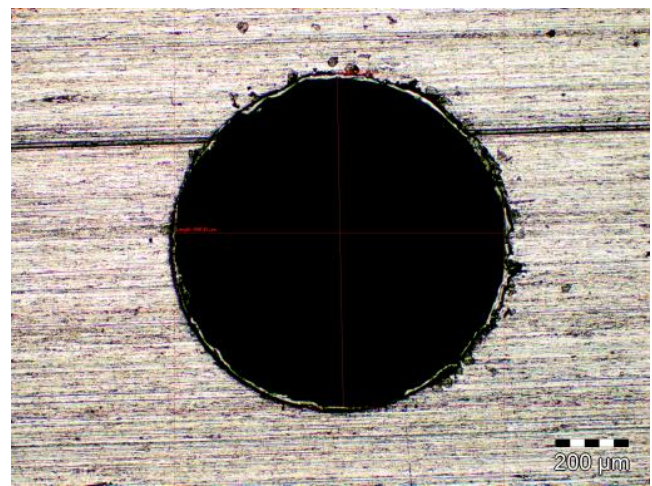

Figure 14: Microscopic image of the $\emptyset 0.9 \mathrm{~mm}$ orifice, 100x magnification

Figures 11-14 represent the results of experimental research by optical microscopy of drill orifices. Using the microscope software, the average diameters were measured, Table 1 showing the difference between the theoretical and measured diameters.

Table 1. Comparison between teoretical and measured diameters of orifices

\begin{tabular}{|c|c|c|}
\hline $\begin{array}{c}\text { Theoretical } \\
\text { diameter } \\
{[\mathrm{mm}]}\end{array}$ & $\begin{array}{c}\text { Average } \\
\text { measured } \\
\text { diameter } \\
{[\mathrm{mm}]}\end{array}$ & $\begin{array}{c}\text { Relative error } \\
{[\%]}\end{array}$ \\
\hline 0.1 & 0.10462 & 4.62 \\
\hline 0.5 & 0.485 & 3 \\
\hline 0.7 & 0.69094 & 1.29 \\
\hline 0.9 & 0.89692 & 0.34 \\
\hline
\end{tabular}

From Figures 11-14 and Table 1 we can conclude that the relative error of the manufacturing of the orifices decreases with the increase in diameter. At the $\varnothing 0.5$ orifice, a surface can be identified on the outline of the resulting orifice due to the formation of another aluminum phase during the machining process. The values of the diameters obtained are in the tolerance field of the execution drawing, and most of the measured diameters are even smaller than the theoretical diameter, which only improves the aeration process, knowing that the oxigenation 
efficiency is greater when the diameters of the holes are smaller. Fig.15 shows the final assembly.

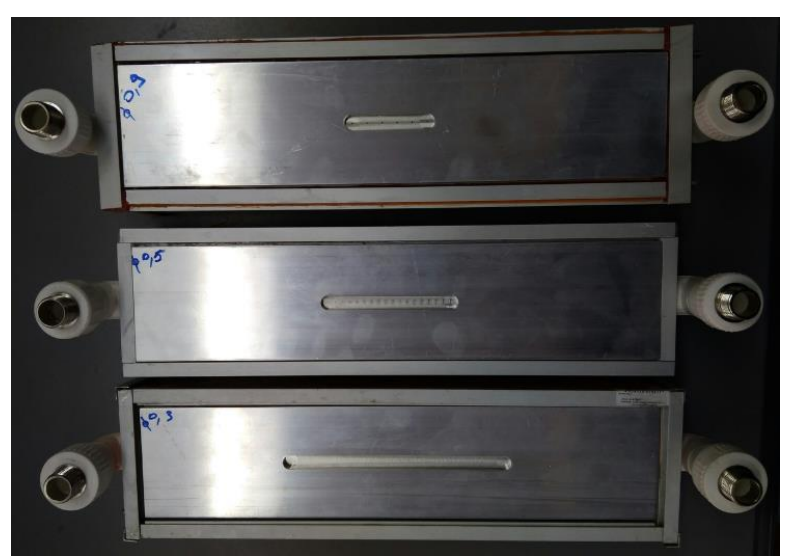

Figure 15 - Final assembly - cassette with plate

\section{Conclusions}

In this paper, the cassettes and plates orifices forming the wastewater element of aeration have been successfully realized with the help of modern additive and subtractive technologies.

Three diffuser cassettes have been obtained using an additive technique consisting in extruding material using two different materials (ABS and PLA) and two different types of 3D printers (Wanhao Duplicator $4 \mathrm{~S}$ and Delta). ABS proved to be a more promising solution for this purpose due to its better appearance and mechanical properties.

Metallic plates with orifices were manufactured using CNC machining, obtaining diameters in the tolerance field prescribed in the drawing. In addition, most of the measured diameters are smaller than the proposed nominal ones; this will positively influence the process of water oxygenation.

After mounting and sealing the plate with orifices on the cassette, the assembly can be installed for subsequent experimental research in the global testing plant of water aeration. It can be concluded that in a short time and with relatively low costs through the modern technologies studied, it is possible to develop an efficient and viable aeration systems.

\section{Acknowledgements}

This work was supported by a grant of the Romanian National Authority for Scientific Research and Innovation, CCCDI - UEFISCDI, project number COFUND-MANUNET III-CEBIOTREAT, within PNCDI III

\section{References}

[1]A. Patulea, Influenţa parametrilor funcţionali şi a arhitecturii generatoarelor de bule fine asupra eficienţei instalaţiilor de aerare, Thesis, 2012, University Politehnica of Bucharest.

[2]O.Dontu, C.I.Moga, B.Tanase, N.Baran, G.I.Gheorghe, E.Moraru, Researches regarding the use of additive technologies in the construction of waer aeration elements, International Journal of Mechatronics and Applied Mechanics, 2018, Issue 3, pp. 7-12.

[3]E.Moraru, D.Besnea, O.Dontu, G.I.Gheorghe, V.Constantin, Applications of additive technologies in realization of customized dental prostheses, International Journal of Mechatronics and Applied Mechanics, 2018, Issue 3, pp.67-71

[4] D.Rizescu, C.Rizescu, Experimental research relating to the manufacture of parts by the addition of material, International Journal of Mechatronics and Applied Mechanics, 2017, Issue 1, pp.193-197

[5] E.Moraru, O.Dontu, A.Petre, D.Vaireanu, F.Constantinescu, D.Besnea, Some technological particularities on the execution of dental prostheses realized by selective laser deposition, 2018, Vol.32, Issue 3-4, pp.208-213

[6]http://solidfill.com/en/Fused_Deposition_Modeli $\mathrm{ng} /$

[7]http://3dprintstory.org/pla-i-abs-dlya-3dpechati-v-chem-raznitsa

[8]http://spegroup.ru/equipment/item/invertirova nnyy_mikroskop_olympus_gx-51/

[9] I.Voiulescu, V.Geanta, R.Stefanoiu, D.Patroi, H.Binchiciu, Influence of the chemical composition on the microstructure and microhardness of AlCrFeCoNi high entropy alloy, Revista de Chimie, Vol.64, No.12 (2013), pp.14411444. 